\title{
Specific Energy: A New Approach to Ultrasound-assisted Extraction of Natural Colorants
}

\author{
Monique Martins Strieder, Eric Keven Silva, M. Angela A. Meireles* \\ LASEFI/DEA/FEA (School of Food Engineering), UNICAMP (University of Campinas), Rua Monteiro Lobato, Campinas-SP, Brazil
}

\begin{abstract}
The demand for natural colorants has boosted the search for innovative technologies to obtain them. Ultrasound-assisted extraction (UAE) is one of the new green techniques that has been studied due to its process advantages that include high yields, short extraction times and nonutilization of elevated temperatures. However, a nonstandardization of the UAE variables complicates comparisons and hinders progress in the studies of this topic. In this review, the focus is the verification and discussion of which UAE process conditions authors have used to obtain natural colorants. Thus, it is possible to confirm that some authors used ultrasonic systems that are not appropriate for performing a good extraction, that some used a great amount of solvent and a long extraction time, and that researchers did not express the main variables (nominal power, extraction time and sample mass) as a function of the specific energy applied to processing. Therefore, it is possible to conclude that some studies using UAE were not conducted to obtain the best results, and the expression of the variables as a function of specific energy can generate a standardization, which facilitates comparison among the results obtained by the scientific community.
\end{abstract}

Keywords Dyes, Sonication, Emerging technology

\section{Introduction}

Colors are an important characteristic of food products, and they awaken people's different expectations [1]. According to Lee, Lee, Lee and Song [2], people perceive a food via their visual perception system, and through that, predict its taste before making a decision about whether or not to purchase it. Because of this, colorants are an important food ingredient, and the global food colorant market is growing - according to Markets and Markets, a growth of approximately $\$ 0.4$ bn is estimated through 2020 [3].

However, the majority of industries utilize synthetic dyes, which have been associated with health problems and cause, for instance, allergies and intolerances, especially in children [4]. Because of this, synthetic food colorants have been progressively replaced by those extracted from natural matrices $[5,6]$. These are mostly carotenoids, anthocyanins, betacyanins and chlorophylls obtained from fruits and others vegetables [7].

Obtaining natural colorants, generally includes, a solid-liquid extraction, which is a separation process that involves mass transference and employs a solvent [8]. The

* Corresponding author:

maameireles@lasefi.com (M. Angela A. Meireles)

Published online at http://journal.sapub.org/fph

Copyright $\odot 2019$ The Author(s). Published by Scientific \& Academic Publishing

This work is licensed under the Creative Commons Attribution International

License (CC BY). http://creativecommons.org/licenses/by/4.0/ solvent utilized for extraction depends on the vegetable matrix, the chemical properties of the pigment and the technic to be employed [9]. In many separation processes performed by industry, large quantities of volatile and flammable organic solvents are used, thus, affecting the environmental and economic performance of the overall extraction [10]. Therefore, currently there is a search for nontoxics solvents that generate less waste and reduce costs $[11,12]$.

In view of new tendencies, green technologies have also been studied for the extraction of different compounds [13]. For the extraction of colorants, techniques include ultrasound [14], microwave [15], pulse electric field [16], pressurized liquids [17] and supercritical fluid processing [18]. Among them, sonochemistry (the principle of ultrasound) has been mentioned as a green chemistry, evidencing various advantages, such as energy savings due to the short time of operation; major yields due to the selectivity; and a reduction in the generation of waste, by the possible use of solvents, including water [19].

The variables in ultrasound-assisted extractions (UAEs) include the system utilized, the matrix and compound to be extracted, the solvent, the proportions of solvent and feed (the amount of solid sample) and the specific energy applied to processing. Specific energy is energy per unit mass expressed as a function of the nominal power and process time. As will be seen in this review, these variables have recently been studied for the obtaining of natural food colorants. However, a lack of standardization in the 
expression of these conditions is observed, for example, the authors did not clearly indicate what specify energy was applied for the extraction.

Thus, in this review, a verification and discussion are performed with respect to the variables used in UAE to obtain natural food colorants. For this, articles published between 2016 and 2018 are reviewed.

\section{Ultrasound Technology}

The utilization of ultrasonic techniques has been increasing over time, and they can be utilized for the analysis (low-intensity) or modification of foods (high-intensity) [20]. High-intensity ultrasound is characterized by the use of a frequency of $20-24 \mathrm{kHz}$ and high levels of power $\left(10-1000 \mathrm{~W} / \mathrm{cm}^{2}\right)$, which physically rupture the materials $[20,21]$.

The principle of this technique involves acoustic cavitation that is promoted by the system. The waves of acoustic energy promote cycles of compression and rarefaction of the molecules in the solution. Through pressure changes occurs the formation and collapse of microbubbles in the medium that result in microjetting. The microjetting generates effects such as surface peeling, erosion and particle breakdown [22, 23], promoting different applications such as the extraction of different compounds [24], microbial and enzymatic inactivation [25], emulsion formation [26] and physical modifications [27]. Among the applications, UAEs have recently been increasingly studied for the acquisition of natural food colorants.

\section{Variables in Colorant Extraction by UAE}

In the achievement of extracts by UAE, the relevant variables include the type of system utilized, the matrix and compound to be extract, the solvent employed, the relation of solvent/feed $(\mathrm{S} / \mathrm{F})$, the temperature and the specific energy applied [28, 29].

The results obtained by some recent studies on the UAE of natural colorants are shown in Table 1, and the variables and the best values as determined by the authors are presented.

\subsection{Ultrasonic System}

The UAE of natural colorants has been performed using a system with a probe (Figure 1-A) or a bath (Figure 1-B) $[23,30]$.

The probe system (Figure 1-A) contains a power generator, a transducer, an amplifier and a probe. The power generator produces high-frequency electrical energy of $20 \mathrm{kHz}$, which is converted to a mechanical energy by the transducer. The mechanical energy is amplified, and further, the acoustic energy is dissipated by the probe in the form of waves [23]. In the bath system (Figure 1-B), consisting of a power generator, a transducer and a bath, the power generator normally produces an energy of $40 \mathrm{kHz}$ [30]. The transducer or transducers dissipate the acoustic energy into bath in the form of waves. In this system, the samples do not receive the waves directly, as is the case in the probe system.

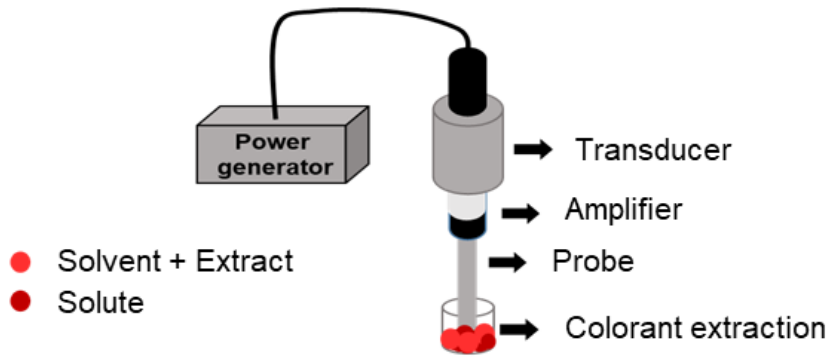

(A)
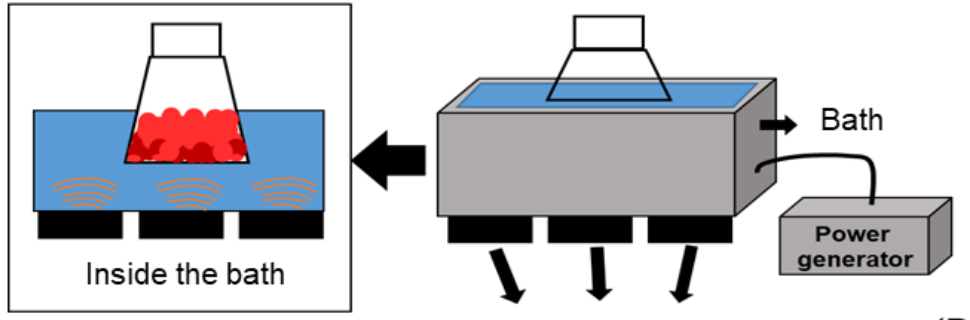

Transducers

(B)

Figure 1. Ultrasonic systems (A: Ultrasound probe), (B: Ultrasound bath)

It is possible to observe in Table 1 that the current research into colorant extractions has been performed using either of the two systems, probe or bath; however, the ultrasonic bath was not the more adequate system for this. The frequencies normally employed in this system are more than $24 \mathrm{kHz}$, such as $37 \mathrm{kHz}$ [31, 32], while the physical effects dominate at lower frequencies [33]. In a study to extract anthocyanins, Cai, Qu, Lan, Zhao, Ma, Wan, Jing and Li [34], using a bath 
ultrasonic system, reported that the UAE is a long-time extraction method and resulted in a low anthocyanin yield. Nevertheless, they used the bath system with an operation frequency of $37 \mathrm{kHz}$, which was not the more adequate system for this purpose.

Apart from the probe and bath systems, some extraction procedures have been performed with a combination of UAE and other techniques. For example, Wizi, Wang, Hou, Tao, Ma and Yang [35] studied the ultrasound-microwave-assisted extraction of natural colorants from sorghum husk. They obtained a yield of 3.6 times that produced via the conventional shaking method. However, the authors used equipment with a frequency of 25 $\mathrm{kHz}$; thus, had a system that generates a lower frequency been used, it is possible the results would have been better.
A combined treatment using a probe system and a cell grinder was realized by Jiang, Yang and Shi [28] to obtain anthocyanins from blueberry. In this work, the authors observed that the cell grinder destroyed the cell walls, which would release water-soluble anthocyanins into any concentration of ethanol.

Comparing the two systems (the probe combined with the cell grinder and the probe), the authors noted some advantages in utilizing the combined technique.

For example, they were able to use water as the only solvent, as well as acquire a higher yield ( 2.12 to $2.89 \mathrm{mg} / \mathrm{g}$ ) and utilize a shorter extraction time (120 to $40 \mathrm{~min}$ ). Most likely, even though the use of combined techniques to obtain the extract promotes a better yield, it is still necessary explore only the high-intensity ultrasound approach.

Table 1. Optimized Variables for the Ultrasound-assisted Extraction of Colorants

\begin{tabular}{|c|c|c|c|c|c|c|c|c|}
\hline $\begin{array}{l}\text { Ultrasonic } \\
\text { System }\end{array}$ & $\begin{array}{l}\text { Matrix/ } \\
\text { Compound }\end{array}$ & Solvent & $\begin{array}{l}\mathrm{S} / \mathrm{F}(\mathrm{w} / \mathrm{w}) \\
\text { Estimated }\end{array}$ & $\begin{array}{c}\text { Temperature } \\
\left({ }^{\circ} \mathrm{C}\right)\end{array}$ & $\begin{array}{c}\text { Process } \\
\text { Time (min) }\end{array}$ & $\begin{array}{l}\text { Power } \\
\text { (W) }\end{array}$ & $\begin{array}{l}\text { Extraction } \\
\text { Yield }\end{array}$ & Ref. \\
\hline Probe & $\begin{array}{c}\text { Rhizomes of } \\
\text { Curcuma/ } \\
\text { Curcumin }\end{array}$ & Ethanol & 25 & 35 & 60 & 250 & $9.18 \mathrm{mg} / \mathrm{g}$ & {$[36]$} \\
\hline Probe & $\begin{array}{c}\text { Pomegranate wastes/ } \\
\text { Carotenoids }\end{array}$ & Soy oil & 10 & 51.5 & 30 & 130 & $\begin{array}{c}0.67 \mathrm{mg} / 100 \\
\mathrm{~g}\end{array}$ & [37] \\
\hline Probe & $\begin{array}{c}\text { Fig peel/ } \\
\text { Anthocyanin }\end{array}$ & Ethanol & 5 & $30-35$ & 21 & 310 & $3.82 \mathrm{mg} / \mathrm{g}$ & {$[38]$} \\
\hline Probe & $\begin{array}{c}\text { Gomphrena globosa L. } \\
\text { /Betacyanins }\end{array}$ & Water & 73 & $\begin{array}{l}\text { uncontrolled } \\
\text { temperature }\end{array}$ & 22 & 500 & $46.9 \mathrm{mg} / \mathrm{g}$ & [39] \\
\hline Probe & $\begin{array}{c}\text { Hibiscus sabdariffa } \\
\text { calyces/ } \\
\text { Anthocyanin }\end{array}$ & Ethanol/ water & 30 & $30-35$ & 45 & 500 & $51.7 \mathrm{mg} / \mathrm{g}$ & {$[40]$} \\
\hline Probe & $\begin{array}{l}\text { Mulberry (Morus nigra) } \\
\text { pulp /Anthocyanins }\end{array}$ & $\begin{array}{l}\text { Methanol/ } \\
\text { Water }\end{array}$ & 8 & 48 & 10 & 200 & $149.9 \mu \mathrm{g} / \mathrm{g}$ & {$[41]$} \\
\hline Probe & $\begin{array}{c}\text { Undaria } \\
\text { pinnatifida/ } \\
\text { Carotenoids and } \\
\text { Chlorophylls }\end{array}$ & Water & 30 & 50 & 30 & 300 & $\begin{array}{c}34 \text { and } 0.5 \\
\mathrm{mg} / \mathrm{mL}\end{array}$ & {$[42]$} \\
\hline Probe & $\begin{array}{c}\text { Red prickly pear peels } \\
\text { and pulps/ betanin and } \\
\text { isobetanin }\end{array}$ & Water & 10 & $\begin{array}{l}\text { uncontrolled } \\
\text { temperature }\end{array}$ & 10 & 400 & $\begin{array}{c}57.47 \\
89.29 \text { and } \\
28.25 \\
\mathrm{mg} / 100 \mathrm{~g}\end{array}$ & {$[43]$} \\
\hline $\begin{array}{l}\text { Probe/ } \\
\text { Probe and } \\
\text { Cell grinder }\end{array}$ & $\begin{array}{c}\text { Blueberry } \\
\text { /Anthocyanins }\end{array}$ & $\begin{array}{l}\text { Ethanol and } \\
\text { Acidified } \\
\text { Water/ } \\
\text { Acidified } \\
\text { Water }\end{array}$ & $\begin{array}{l}20 \\
25\end{array}$ & 25 & $\begin{array}{c}120 \\
40\end{array}$ & $\begin{array}{l}1800 \\
1500\end{array}$ & $\begin{array}{c}2.12 \text { and } \\
2.89 \mathrm{mg} / \mathrm{g}\end{array}$ & {$[28]$} \\
\hline Bath & $\begin{array}{l}\text { Purple sweet potatoes/ } \\
\text { Anthocyanins }\end{array}$ & Ethanol/ water & 10 & 60 & 60 & 200 & $\begin{array}{c}214.92 \\
\mathrm{mg} / 100 \mathrm{~g}\end{array}$ & {$[34]$} \\
\hline Bath & $\begin{array}{l}\text { Wine lees/ } \\
\text { Anthocyanins }\end{array}$ & $\begin{array}{c}\text { Choline } \\
\text {-chloride-with } \\
\text { Malic } \\
\text { Acid/Water }\end{array}$ & 10 & 35 & 30.6 & 341.5 & $6.55 \mathrm{mg} / \mathrm{g}$ & [31] \\
\hline Bath & $\begin{array}{l}\text { Residues of Rubus } \mathrm{f} \\
\text { ruticosus, Vaccinium } \\
\text { myrtillus and Eugenia } \\
\text { brasiliensis/ } \\
\text { Anthocyanins }\end{array}$ & Ethanol/ Water & 20 & 80 & 90 & 580 & $\begin{array}{c}2.38,2.33 \\
\text { and } 0.87 \\
\mathrm{mg} / \mathrm{g}\end{array}$ & {$[32]$} \\
\hline
\end{tabular}




\subsection{Matrix and Compound}

Vegetables are a typical resource in research for various applications, due to the vast diversity of molecules [44]. However, some care must be taken to avoid variations due to the matrix. For example, depending on its cultivar, the fig acquires different colors as a function of the anthocyanin concentration [45].

Furthermore, the compounds to be extracted showed different tolerances and peculiarities. For example, anthocyanins are sensitive to temperature, $\mathrm{pH}$, light, oxygen and metals, which must be considered during the separation processes to avoid loss [46]. Additionally, curcumin, according Heger, van Golen, Broekgaarden and Michel [47], degrades in the presence of sunlight and visible light.

\subsection{Solvent and Feed}

The physical properties of the mixture (solvent and feed) strongly influence the effectiveness of the cavitation, which needs to be proper for acoustic energy transference. For example, the solvent characteristics affect the cavitation phenomenon: the steam pressure governs the intensity of the bubble collapse, and the surface tension and viscosity govern the transient threshold of cavitation [33].

With respect to the solvent, it should be well-matched with the compound [48]. For example, the anthocyanins are normally stable under acidic conditions, and because of this, employing acidified ethanol as the solvent is an option [28]. Carotenoids possess nonpolar characteristics; thus, a good option, according to Goula, Ververi, Adamopoulou and Kaderides [37], is the utilization of vegetable oils.

Machado, Pereira, Barbero and Martínez [32] demonstrated the importance in the choice of solvent to be employed. Obtaining anthocyanins from residues of Rubus fruticosus, Vaccinium myrtillus and Eugenia brasiliensis, the authors observed different results using different solvents (water or ethanol). They observed that using water as solvent, higher extracts yields were obtained, but in relation to the antioxidant activity, they verified the opposite. The colorants in ethanol showed a higher antioxidant activity (determined using in vitro methods) than did the ones obtained with water. This phenomenon, according the authors, occurs because more compounds are soluble in water, but not the target compounds.

In addition, the solvent utilized must be GRAS (generally regarded as safe) [49] and minimize the environmental impact. In Table 1, it is possible to observe that most of the research has been performed using green solvents such as water and ethanol. Nevertheless, some, including Shirsath and Sable (23), still studied solvents such as methanol and acetone to perform the ultrasound-assisted extractions. However, the majority of authors used GRAS solvents to do the extractions, which demonstrates a tendency in the utilization of green solvents over toxic organic solvents [50].

The amount of solvent employed is also very important to obtain an efficient extraction, but an excessive quantity must be avoided to minimize the environmental impact. Table 1 shows that a large amount of the solvent was still used. Considering that in some studies $\mathrm{S} / \mathrm{F}$ relations of 5 and 8 were utilized, a relation of 73 is extremely high and must be reduced to avoid the generation of a great amount of effluent.

Backes, Pereira, Barros, Prieto, Genena, Barreiro and Ferreira [38] observed that the relation of S/F is extremely important to obtain a pure extract of anthocyanin pigments from Ficus carica. Out of the values of S/F studied, the of 5 obtained the best results. This result indicated the possibility of obtaining good extraction results using a low relation of $\mathrm{S} / \mathrm{F}$.

\subsection{Temperature}

In addition to the cavitation and mechanical effects, the thermal effects also have a significant influence on the UAE [51]. Thus, the temperature is another important variable in the extraction.

In previous studies, high-intensity ultrasound was verified as an economically feasible technology for the extraction of thermolabile compounds, but with long extractions time, it is important to pay attention to this factor. [43]. During the extraction process, there is a fast rise in the temperature of the reaction system [40]. The temperature can increase considerably, and the process can be characterized as thermal.

The increase in temperature can be favorable for the extraction of some dyes, but not for others. For example, Zhu, Wu, Di, Li, Barba, Koubaa, Roohinejad, Xiong and He [42] observed that with an increase of $10^{\circ} \mathrm{C}\left(40\right.$ to $\left.50^{\circ} \mathrm{C}\right)$, the carotenoid yield increased by $8 \%$; however, with a major increase, the yield was reduced. This result was attributed to the degradation of thermolabile carotenoids. On the other hand, the chlorophylls' recovery showed a positive increase with the temperature $\left(40\right.$ to $\left.60^{\circ} \mathrm{C}\right)$.

It is possible to observe in Table 1 that most of the processes recently studied were performed at controlled temperatures. The evaluated temperatures varied from 25 to $80^{\circ} \mathrm{C}$; however, in some studies, the temperature was not controlled. It is necessary to emphasize that temperature control is particularly important, especially when working with thermolabile compounds. For example, in the extraction process realized by Roriz, Barros, Prieto, Barreiro, Morales and Ferreira [39], the temperature not was controlled, but they extracted betacyanins, which are thermolabile compounds [52].

\subsection{Specific Energy}

The energy densities applied by ultrasound in food processes have been standardized by some researchers according to Equation $1[26,53,54]$. It is possible to observe in Equation 1 that the energy applied in the processes depends on the nominal power, the extraction time and the sample volume. However, the volume is a function of the pressure and temperature, and because of that, another way to express the energy is as a function of mass, which does not depend on other variables. This relation is expressed in 
specific energy (Equation 2), according Rajha, Boussetta, Louka, Maroun and Vorobiev [55].

$$
\begin{aligned}
& E D=\left(\frac{J}{m L}\right)=\frac{\text { Nominal power }(W) \times \text { Extraction time }(s]}{\text { Sample volume }(m L)} \\
& E=\left(\frac{J}{g}\right)=\frac{\text { Nominal power }(W) \times \text { Extraction time }(s)}{\text { Sample mass }(g)}
\end{aligned}
$$

\subsubsection{Nominal Power}

The nominal power is the power provided by the ultrasound device itself; however, this is not exactly the same value that is converted into the cavitation phenomenon [56]. This occurs due to energy loss in the equipment by dissipation during the subsequent conversions of mechanical energy into cavitation. According to Mamvura, Iyuke and Paterson [57], an energy conversion from electrical to cavitation of $9 \%$ was achieved. Shirsath, Sable, Gaikwad, Sonawane, Saini and Gogate [36] also verified through a calorimetric method that the energy efficiency of the process was approximately $5.6 \%$. Because of that, most authors have used the highest nominal power of the equipment to do the extractions [37].

A high nominal power causes great shear forces in plant materials that results from the critical pressure and temperature obtained from the oscillation and collapse of cavitation bubbles within the solvent [40]. Thus, high values of the nominal power normally result in high extraction yields.

In the majority of the studies shown in Table 1, higher nominal powers were selected as the best condition for the extractions. According to Zhu, Wu, Di, Li, Barba, Koubaa, Roohinejad, Xiong and He [42], better results for obtaining pigments are achieved with more intense ultrasonic treatments, mainly due to the cavitation effect of ultrasound.

\subsubsection{Extraction Time}

The extraction time is directly associated with the nominal power supplied by the ultrasound and the samples mass (solvent and feed), as given by Equation 2. Therefore, the effect of time on the extraction is one of the most important factors; if the samples are exposed to shorter or longer times than suitable, the compounds could be degraded or not be completely extracted [39].

Thus, the time to be employed depends of the other variables. For example, Espada-Bellido, Ferreiro-González, Carrera, Palma, Barroso and Barbero [41] observed that to recover anthocyanin from mulberry, the maximum time was $10 \mathrm{~min}$. According to them, this time was sufficient for a quantitative extraction and to avoid anthocyanin degradation. However, the time can probably be reduced when using a higher nominal power (greater than $200 \mathrm{~W}$ ).

It is possible to verify in Table 1 which extractions used a long time (up to $120 \mathrm{~min}$ ). This time can be reduced substantially. From Equation 1, it is possible that a high nominal power and a small sample mass can result in a short extraction time.

\subsubsection{Sample Weight or Volume}

Another criticism lies with the relationship of the sample employed in the ultrasound-assisted extractions. The majority of the studies expressed values in terms of the volume and this term is not the more suitable, considering that it can change with the temperature (Boyle-Mariotte law).

Beyond that, it is possible observe that a great amount of solvent was used in relation to a little amount of feed (Table 1). This implies that little energy was applied to the sample, decreasing the friction between the particles. The friction causes cellular rupture and the release of the compounds of interest, thus, assisting the extraction.

\subsubsection{The Variable Combinations}

It is important to observe the combinations of the main variables through the specific energy (E) value (Equation 2), which permits an easy understanding of the UAE process employed. The $\mathrm{E}$ value relates the variables of time, nominal power and sample mass and clearly represents the energy involved in the process. Furthermore, typically, a bigger $\mathrm{E}$ value results in the best extraction yield.

It is possible to observe some combinations in Table 1. Goula, Ververi, Adamopoulou and Kaderides [37] utilized a longer time (30 $\mathrm{min})$ but a smaller nominal power $(130 \mathrm{~W})$ for extraction; while Koubaa, Barba, Grimi, Mhemdi, Koubaa, Boussetta and Vorobiev [43], using the same S/F (10), used a shorter time (10 min) and a larger nominal power $(400 \mathrm{~W})$ to obtain the dye extract.

However, the authors did not express the E value utilized and doing so would have favored a comparison of the extractions realized. In the papers reviewed, it is possible to verify that only Koubaa, Barba, Grimi, Mhemdi, Koubaa, Boussetta and Vorobiev [43] approached the process by regarding the specific energy utilized in the UAE; however, the authors did not connect the specific energy to the extraction time, thus, expressing the specific energy input in $\mathrm{kJ} / \mathrm{kg}$.

\section{Quality of Dyes Obtained by UAE}

Extracts from vegetables contain bioactive compounds that are valuable to the nutraceutical fields, and because of this, the extraction process is a crucial step that needs to ensure that the active ingredients are not lost or destroyed during its operation [58]. Among the methods recently revised by Náthia-Neves and Meireles [59] to obtain natural colorants, the UAE is prominent because of the high purity of the final product. Thus, it is worth noting that in addition to obtaining high yields, it is also interesting to obtain pure extracts that facilitate the material's application.

The ultrasound efficiency was observed by Koubaa, Barba, Grimi, Mhemdi, Koubaa, Boussetta and Vorobiev 
[43], who verified a cell denaturation after ultrasound treatment via scanning electron microscopy. According to the authors, this result can provide a better recovery of the intracellular compounds with less impurities [43]. The best results were obtained by [Backes, Pereira, Barros, Prieto, Genena, Barreiro and Ferreira [38]] who related that the UAE technique led to an extract with a greater purity of cyanidin 3-rutinoside in comparison with that of extractions assisted by heat and microwave.

Machado, Pereira, Barbero and Martínez [32] observed that among the emergent methods, UAE was the least aggressive in recovering total and individual anthocyanins, followed by the others studied, UAE + pressurized liquid (PLE) and PLE, using hydroethanolic mixtures as the solvent.

Thus, it was possible verify that ultrasound-assisted extractions are a good choice to obtain adequate results in terms of yield and quality of colorant extracts.

\section{Conclusions}

In this review, an evaluation of the variables that have been used in the ultrasound-assisted extractions is made, and some important aspects are observed:

$\checkmark$ It is important to know the stability of the compound to be extracted to avoid loss due to the extraction operation.

$\checkmark$ The solvent to be employed should be compatible with the compound of interest, be a GRAS, and be in a smaller amount than the majority of the studies have been using.

$\checkmark$ The variation in temperature must be controlled during the process of extraction.

$\checkmark$ The extraction time can be reduced by using a high nominal power.

$\checkmark$ Larger nominal power values generate higher extraction yields.

$\checkmark$ The best manner is to express the amount of solvent and feed in units of mass.

$\checkmark$ The colorants obtained by UAE showed a high quality.

At the end of this review, is possible to suggest that the variables of nominal power, extraction time and sample mass are expressed in terms of the specific energy to standardize the form of expressing the energy applied to the sample. Thus, a comparison among the results of ultrasound-assisted extraction of colorants would be facilitated.

\section{ACKNOWLEDGEMENTS}

Monique Martins Strieder thanks CNPq (141110/2018-0) for the Ph.D. scholarship. Eric Keven Silva thanks FAPESP (2015/22226-6) for the postdoctoral scholarship. M. Angela A. Meireles thanks CNPq (302423/2015-0) for the productivity grant.

\section{REFERENCES}

[1] Spence, C., 2018, Background colour \& its impact on food perception \& behaviour, Food Quality and Preference, 68, 156-166.

[2] Lee, S.-M., Lee, K.-T., Lee, S.-H., Song, J.-K., 2013, Origin of human colour preference for food, Journal of Food Engineering, 119, 508-515.

[3] Markets and Markets, 2017, Agricultural colorants market worth $\$ 2.03$ bn by 2022 , Focus on Pigments, 2-3.

[4] Feketea, G., Tsabouri, S., 2017, Common food colorants and allergic reactions in children: Myth or reality?, Food Chemistry, 230, 578-588.

[5] Martins, N., Roriz, C. L., Morales, P., Barros, L., Ferreira, I. C. F. R., 2016, Food colorants: Challenges, opportunities and current desires of agro-industries to ensure consumer expectations and regulatory practices, Trends in Food Science \& Technology, 52, 1-15.

[6] Vinha, A. F., Rodrigues, F., Nunes, M. A., Oliveira, M. B. P., 2018, 11 - Natural pigments and colorants in foods and beverages, in: C.M. Galanakis (Ed.) Polyphenols: Properties, Recovery, and Applications, Woodhead Publishing, 363-391.

[7] Rodriguez-Amaya, D. B., 2016, Natural food pigments and colorants, Current Opinion in Food Science, 7, 20-26.

[8] Z. Berk, Extraction, Food Process Engineering and Technology (Third Edition), 2018, pp. 289-310.

[9] Yan, J.-K., Ding, Z.-C., Gao, X., Wang, Y.-Y., Yang, Y., Wu, D., Zhang, H.-N., 2018, Comparative study of physicochemical properties and bioactivity of Hericium erinaceus polysaccharides at different solvent extractions, Carbohydrate polymers, 193, 373-382.

[10] Bubalo, M. C., Vidović, S., Redovniković, I. R., Jokić, S., 2018, New perspective in extraction of plant biologically active compounds by green solvents, Food and Bioproducts Processing, 109, 52-73.

[11] Bitencourt, A. P., Duarte, J. L., Oliveira, A. E., Cruz, R. A., Carvalho, J. C., Gomes, A. T., Ferreira, I. M., Ribeiro-Costa, R. M., Silva-Júnior, J. O., Fernandes, C. P., 2018, Preparation of aqueous nanodispersions with annatto (Bixa orellana L.) extract using an organic solvent-free and low energy method, Food chemistry, 257, 196-205.

[12] Lemos, D. A., Sonego, J. L. S., Boschiero, M. V., Araujo, E. C. C., Cruz, A. J. G., Badino, A. C., 2017, Selection and application of nontoxic solvents in extractive ethanol fermentation, Biochemical Engineering Journal, 127, 128-135.

[13] Chemat, F., Rombaut, N., Meullemiestre, A., Turk, M., Perino, S., Fabiano-Tixier, A.-S., Abert-Vian, M., 2017, Review of Green Food Processing techniques. Preservation, transformation, and extraction, Innovative Food Science \& Emerging Technologies, 41, 357-377.

[14] López, C. J., Caleja, C., Prieto, M. A., Barreiro, M. F., Barros, L., Ferreira, I. C. F. R., 2018, Optimization and comparison of heat and ultrasound assisted extraction techniques to obtain 
anthocyanin compounds from Arbutus unedo L. Fruits, Food Chemistry, 264, 81-91.

[15] Thirugnanasambandham, K., Sivakumar, V., 2017, Microwave assisted extraction process of betalain from dragon fruit and its antioxidant activities, Journal of the Saudi Society of Agricultural Sciences, 16, 41-48.

[16] Martínez, J. M., Luengo, E., Saldaña, G., Álvarez, I., Raso, J., 2017, C-phycocyanin extraction assisted by pulsed electric field from Artrosphira platensis, Food Research International, 99, 1042-1047.

[17] Osorio-Tobón, J. F., Carvalho, P. I. N., Rostagno, M. A., Meireles, M. A. A., 2016, Process integration for turmeric products extraction using supercritical fluids and pressurized liquids: Economic evaluation, Food and Bioproducts Processing, 98, 227-235.

[18] Fathordoobady, F., Mirhosseini, H., Selamat, J., Manap, M. Y. A., 2016, Effect of solvent type and ratio on betacyanins and antioxidant activity of extracts from Hylocereus polyrhizus flesh and peel by supercritical fluid extraction and solvent extraction, Food Chemistry, 202, 70-80.

[19] Chatel, G., 2018, How sonochemistry contributes to green chemistry?, Ultrasonics Sonochemistry, 40, 117-122.

[20] D. J. McClements, 1995, Advances in the application of ultrasound in food analysis and processing, Trends in Food Science \& Technology, 6, 1995 293-299.

[21] Abbas, S., Hayat, K., Karangwa, E., Bashari, M., Zhang, X., 2013, An overview of ultrasound-assisted food-grade nanoemulsions, Food Engineering Reviews, 5, 139-157.

[22] Ashokkumar, M., 2015, Applications of ultrasound in food and bioprocessing, Ultrasonics sonochemistry, 25, 17-23.

[23] Silva, E. K., Rosa, M. T. M. G., Meireles, M. A. A., 2015, Ultrasound-assisted formation of emulsions stabilized by biopolymers, Current Opinion in Food Science, 5, 50-59.

[24] Luo, Y., Peng, B., Liu, Y., Wu, Y., Wu, Z., 2018, Ultrasound extraction of polysaccharides from guava leaves and their antioxidant and antiglycation activity, Process Biochemistry, $73,228-234$.

[25] Monteiro, S. H. M. C., Silva, E. K., Alvarenga, V. O., Moraes, J., Freitas, M. Q., Silva, M. C., Raices, R. S. L., Sant'Ana, A. S., Meireles, M. A. A., Cruz, A. G., 2018, Effects of ultrasound energy density on the non-thermal pasteurization of chocolate milk beverage, Ultrasonics Sonochemistry, 42, $1-10$.

[26] Silva, E. K., Costa, A. L. R., Gomes, A., Bargas, M. A., Cunha, R. L., Meireles, M. A. A., 2018, Coupling of high-intensity ultrasound and mechanical stirring for producing food emulsions at low-energy densities, Ultrasonics Sonochemistry, 47, 114-121.

[27] Monroy, Y., Rivero, S., García, M. A., 2018, Microstructural and techno-functional properties of cassava starch modified by ultrasound, Ultrasonics Sonochemistry, 42, 795-804.

[28] Jiang, H.-L., Yang, J.-L., Shi, Y.-P., 2017, Optimization of ultrasonic cell grinder extraction of anthocyanins from blueberry using response surface methodology, Ultrasonics Sonochemistry, 34, 325-331.

[29] Albuquerque, B. R., Prieto, M. A., Barreiro, M. F., Rodrigues,
A., Curran, T. P., Barros, L., Ferreira, I. C. F. R., 2017, Catechin-based extract optimization obtained from Arbutus unedo L. fruits using maceration/microwave/ultrasound extraction techniques, Industrial Crops and Products, 95, 404-415.

[30] Chemat, F., Rombaut, N., Sicaire, A.-G., Meullemiestre, A., Fabiano-Tixier, A.-S., Abert-Vian, M., 2017, Ultrasound assisted extraction of food and natural products. Mechanisms, techniques, combinations, protocols and applications. A review, Ultrasonics Sonochemistry, 34, 540-560.

[31] Bosiljkov, T., Dujmić, F., Cvjetko Bubalo, M., Hribar, J., Vidrih, R., Brnčić, M., Zlatic, E., Radojčić Redovniković, I., Jokić, S., 2017, Natural deep eutectic solvents and ultrasound-assisted extraction: Green approaches for extraction of wine lees anthocyanins, Food and Bioproducts Processing, 102, 195-203.

[32] Machado, A. P. D. F., Pereira, A. L. D., Barbero, G. F., Martínez, J., 2017, Recovery of anthocyanins from residues of Rubus fruticosus, Vaccinium myrtillus and Eugenia brasiliensis by ultrasound assisted extraction, pressurized liquid extraction and their combination, Food Chemistry, 231, $1-10$.

[33] Tiwari, B. K., 2015, Ultrasound: A clean, green extraction technology, TrAC Trends in Analytical Chemistry, 71, 100-109.

[34] Cai, Z., Qu, Z., Lan, Y., Zhao, S., Ma, X., Wan, Q., Jing, P., Li, P., 2016, Conventional, ultrasound-assisted, and accelerated-solvent extractions of anthocyanins from purple sweet potatoes, Food Chemistry, 197, 266-272.

[35] Wizi, J., Wang, L., Hou, X., Tao, Y., Ma, B., Yang, Y., 2018, Ultrasound-microwave assisted extraction of natural colorants from sorghum husk with different solvents, Industrial Crops and Products, 120, 203-213.

[36] Shirsath, S., Sable, S., Gaikwad, S., Sonawane, S., Saini, D., Gogate, P., 2017, Intensification of extraction of curcumin from Curcuma amada using ultrasound assisted approach: Effect of different operating parameters, Ultrasonics sonochemistry, 38, 437-445.

[37] Goula, A. M., Ververi, M., Adamopoulou, A., Kaderides, K., 2017, Green ultrasound-assisted extraction of carotenoids from pomegranate wastes using vegetable oils, Ultrason Sonochem, 34, 821-830.

[38] Backes, E., Pereira, C., Barros, L., Prieto, M. A., Genena, A. K., Barreiro, M. F., Ferreira, I. C. F. R., 2018, Recovery of bioactive anthocyanin pigments from Ficus carica L. peel by heat, microwave, and ultrasound based extraction techniques, Food Research International, 113, 197-209.

[39] Roriz, C. L., Barros, L., Prieto, M. A., Barreiro, M. F., Morales, P., Ferreira, I. C. F. R., 2017, Modern extraction techniques optimized to extract betacyanins from Gomphrena globosa L, Industrial Crops and Products, 105, 29-40.

[40] Pinela, J., Prieto, M. A., Pereira, E., Jabeur, I., Barreiro, M. F., Barros, L., Ferreira, I. C. F. R., 2019, Optimization of heatand ultrasound-assisted extraction of anthocyanins from Hibiscus sabdariffa calyces for natural food colorants, Food Chemistry, 275, 309-321.

[41] Espada-Bellido, E., Ferreiro-González, M., Carrera, C., Palma, M., Barroso, C. G., Barbero, G. F., 2017, Optimization of the ultrasound-assisted extraction of anthocyanins and total 
phenolic compounds in mulberry (Morus nigra) pulp, Food chemistry, 219, 23-32.

[42] Zhu, Z., Wu, Q., Di, X., Li, S., Barba, F. J., Koubaa, M., Roohinejad, S., Xiong, X., He, J., 2017, Multistage recovery process of seaweed pigments: Investigation of ultrasound assisted extraction and ultra-filtration performances, Food and Bioproducts Processing, 104, 40-47.

[43] Koubaa, M., Barba, F. J., Grimi, N., Mhemdi, H., Koubaa, W., Boussetta, N., Vorobiev, E., 2016, Recovery of colorants from red prickly pear peels and pulps enhanced by pulsed electric field and ultrasound, Innovative Food Science \& Emerging Technologies, 37, 336-344.

[44] de Melo, M. M. R., Silvestre, A. J. D., Silva, C. M., 2014, Supercritical fluid extraction of vegetable matrices: Applications, trends and future perspectives of a convincing green technology, The Journal of Supercritical Fluids, 92, 115-176.

[45] Cao, L., Xu, X., Chen, S., Ma, H., 2016, Cloning and expression analysis of Ficus carica anthocyanidin synthase 1 gene, Scientia Horticulturae, 211, 369-375.

[46] Jackman, R. L., Yada, R. Y., Tung, M. A., Speers, R. A., 1987, Anthocyanins as food colorants-a review, Journal of food biochemistry, 11, 201-247.

[47] Heger, M., van Golen, R. F., Broekgaarden, M., Michel, M. C., 2014, The molecular basis for the pharmacokinetics and pharmacodynamics of curcumin and its metabolites in relation to cancer, Pharmacological reviews, 66, 222-307.

[48] Lupacchini, M., Mascitti, A., Giachi, G., Tonucci, L., d'Alessandro, N., Martinez, J., Colacino, E., 2017, Sonochemistry in non-conventional, green solvents or solvent-free reactions, Tetrahedron, 73, 609-653.

[49] J. L. Frestedt, Chapter 16 - Foods, Food Additives, and Generally Regarded as Safe (GRAS) Food Assessments, in: A.M. Holban, A.M. Grumezescu (Eds.) Food Control and Biosecurity, Academic Press, 2018, pp. 543-565.

[50] Hamany Djande, C. Y., Piater, L. A., Steenkamp, P. A., Madala, N. E., Dubery, I. A., 2018, Differential extraction of phytochemicals from the multipurpose tree, Moringa oleifera, using green extraction solvents, South African Journal of Botany, 115, 81-89.
[51] Wen, C., Zhang, J., Zhang, H., Dzah, C. S., Zandile, M., Duan, Y., Ma, H., Luo, X., 2018, Advances in ultrasound assisted extraction of bioactive compounds from cash crops-A review, Ultrasonics sonochemistry, 48, 538-549.

[52] Castellar, R., Obón, J. M., Alacid, M., Fernández-López, J. A., 2003, Color properties and stability of betacyanins from Opuntia fruits, Journal of agricultural and food chemistry, 51, 2772-2776.

[53] Arruda, H. S., Silva, E. K., Pereira, G. A., Angolini, C. F. F., Eberlin, M. N., Meireles, M. A. A., Pastore, G. M., 2018, Effects of high-intensity ultrasound process parameters on the phenolic compounds recovery from araticum peel, Ultrasonics sonochemistry, 50, 82-95.

[54] Guimarães, J. T., Silva, E. K., Alvarenga, V. O., Costa, A. L. R., Cunha, R. L., Sant'Ana, A. S., Freitas, M. Q., Meireles, M. A. A., Cruz, A. G., 2018, Physicochemical changes and microbial inactivation after high-intensity ultrasound processing of prebiotic whey beverage applying different ultrasonic power levels, Ultrasonics Sonochemistry, 44, 251-260.

[55] Rajha, H. N., Boussetta, N., Louka, N., Maroun, R. G., Vorobiev, E., 2014, A comparative study of physical pretreatments for the extraction of polyphenols and proteins from vine shoots, Food Research International, 65, 462-468.

[56] Wang, W., Chen, W., Zou, M., Lv, R., Wang, D., Hou, F., Feng, H., Ma, X., Zhong, J., Ding, T., Ye, X., Liu, D., 2018, Applications of power ultrasound in oriented modification and degradation of pectin: A review, Journal of Food Engineering, 234, 98-107.

[57] Mamvura, T. A., Iyuke, S. E., Paterson, A. E., 2018, Energy changes during use of high-power ultrasound on food grade surfaces, South African Journal of Chemical Engineering, 25, 62-73.

[58] Yahya, N. A., Attan, N., Wahab, R. A., 2018, An overview of cosmeceutically relevant plant extracts and strategies for extraction of plant-based bioactive compounds, Food and Bioproducts Processing, 112, 69-85.

[59] Náthia-Neves, G., Meireles, M. A. A., 2018, Genipap: A New Perspective on Natural Colorants for the Food Industry, Food and Public Health, 8, 21-33. 